\title{
VESTIBOLOGY
}

\section{Occlusal splint therapy in patients with Ménière's disease and temporomandibular joint disorder}

\section{La terapia occlusale nei pazienti con malattia di Ménière e disordini dell'articolazione temporomandibolare}

\author{
Daniele Monzani', Carlo Baraldi,3, Enrico Apa', Matteo Alicandri-Ciufelli ${ }^{1}$, Carlo Bertoldi' ${ }^{4}$, Elisabeth Röggla ${ }^{5}$, \\ Simona Guerzoni ${ }^{3}$, Daniele Marchioni ${ }^{6}$, Luca Pani3,7,8,9 \\ ${ }^{1}$ Otolaryngology Unit, Department of Medical, Surgical and Pediatric Sciences, University of Modena and Reggio Emilia, Modena, Italy; \\ 2 School in Neurosciences, Department of Biomedical, Metabolic and Neural Sciences, University of Modena and Reggio Emilia, Modena, \\ Italy; ${ }^{3}$ Medical Toxicology-headache and Drug Abuse Research Center, Department of Biomedical, Metabolic and Neural Sciences, University \\ of Modena and Reggio Emilia, Modena, Italy; ${ }^{4}$ Dentistry and Oro-maxillofacial Surgery Unit, Department of Surgery, Medicine, Dentistry, \\ Transplantation Morphology, Oncology and Regenerative Medicine, University of Modena and Reggio Emilia, Modena, Italy; 5 Poliambulatorio \\ Elios, Modena, Italy; ${ }^{6}$ Otolaryngology Unit, Department of Surgical, Odontostomatologic and Pediatric Sciences, University of Verona, Verona, \\ Italy; ${ }^{7}$ Pharmacology Unit, Department of Biomedical, Metabolic and Neural Sciences, University of Modena and Reggio Emilia, Modena, \\ Italy; ${ }^{8}$ Department of Psychiatry and Behavioral Sciences, University of Miami, Miami, USA; ${ }^{9}$ VeraSci, Durham, NC, USA
}

\section{SUMMARY}

Objective. This retrospective study aimed to verify the outcomes of stabilising occlusal splint therapy prescribed to 22 patients with unilateral definite Ménière's disease and comorbid temporomandibular joint disorder.

Methods. The results of a battery of audiometric and vestibular tests were recorded before and after 6 months of treatment, as well as the scores of disease-specific questionnaires.

Results. The average hearing threshold in the affected ear and the acoustic immittance were unchanged. No spontaneous and positional nystagmus were recorded. Caloric hyporesponsiveness and vestibular myogenic evoked responses did not vary. No changes of stabilometric body sway parameters in eyes opened condition and with optokinetic stimulation delivered to the unaffected labyrinth were observed. A significant reduction was recorded in eyes closed condition and with the optokinetic stimulation toward the affected ear. The Tinnitus Handicap Inventory, the Situational Vertigo Questionnaire and the Numeric Pain Rating Scale scores improved. The number of vertigo attacks was reduced.

Conclusions. Occlusal splint therapy is a favourable option to reduce aural symptoms of Ménière's disease and comorbid temporomandibular joint disorder, even if its pathophysiological mechanism remains elusive.

KEY WORDS: temporomandibular joint disorder, Ménière's disease, occlusal splint, vertigo, headache

\section{RIASSUNTO}

Obiettivo. Questo studio esplora gli effetti dello splint occlusale in 22 pazienti affetti da malattia di Ménière monolaterale e disturbi dell'articolazione temporo-mandibolare.

Metodi. I pazienti sono stati sottoposti a diversi test audiometrici e vestibolari prima e dopo sei mesi di trattamento con splint occlusale, oltre a questionari specifici per la malattia di Ménière. Risultati. La soglia uditiva media nell'orecchio malato e l'impedenza acustica sono rimaste invariate e non è stato registrato nessun nistagmo clinicamente significativo. I potenziali evocati miogenici non hanno subito variazioni. Il numero di crisi di vertigine si è ridotto significativamente durante il trattamento $(p=0,003)$. I parametri stabilometrici misurati ad occhi chiusi e con la stimolazione otticocinetica verso il labirinto malato $(p 0,0001)$ sono significativamente migliorati. I punteggi del Situational Vertigo Questionnaire $(p=0,002)$, del Tinnitus Handicap Inventory $(p<0,0001)$ e del Numeric Pain Rating Scale $(p<0,0001)$ sono migliorati. Conclusioni. La terapia con splint occlusale è efficace nel ridurre alcuni sintomi della malattia di Ménière in comorbidità con il disordine dell'articolazione temporomandibolare, anche se il suo meccanismo fisiopatologico rimane indeterminato.

PAROLE CHIAVE: disordine dell'articolazione temporo-mandibolare, malattia di Ménière, splint occlusale, vertigine, cefalea
Received: April 27, 2021

Accepted: September 19, 2021

Published online: February 7, 2022

\section{Correspondence}

Carlo Baraldi

Medical Toxicology-headache and Drug Abuse Research Center, Department of Biomedical, Metabolic and Neural Sciences, University of Modena and Reggio Emilia

via del Pozzo 71, 41124 Modena, Italy

Tel.+390594 222104. Fax +390594222454

E-mail: infocarlo.baraldi@gmail.com

How to cite this article: Monzani D, Baraldi C, Apa E, et al. Occlusal splint therapy in patients with Ménière's disease and temporomandibular joint disorder. Acta Otorhinolaryngol Ital 2022;42:89-96. https://doi. org/10.14639/0392-100X-N1641

(c) Società Italiana di Otorinolaringoiatria e Chirurgia Cervico-Facciale

\section{(c) (1) () $\odot$}

This is an open access article distributed in accordance with the CC-BY-NC-ND (Creative Commons Attribution-NonCommercial-NoDerivatives 4.0 International) license. The article can be used by giving appropriate credit and mentioning the license, but only for non-commercial purposes and only in the original version. For further information: https:// creativecommons.org/licenses/by-nc-nd/4.0/deed.en 


\section{Introduction}

Temporomandibular joint disorders (TMDs) are a group of common musculoskeletal dysfunctions involving the temporomandibular joint (TMJ) and the associated musculature. The aetiology of TMDs is multifactorial: dental occlusion abnormalities, masticatory parafunctions, degenerative or inflammatory conditions involving TMJ, traumatic injuries, inappropriate orthodontic treatments, psychological distress and oestrogen levels that may act alone or simultaneously ${ }^{1}$. Possible clinical symptoms related to TMD are pain and/or noise at the temporomandibular joint as well as pain and/ or tenderness perceived across jaw and masticatory muscles. These symptoms may cause limitation of the mandibular movements, thus reducing the patients' quality of life ${ }^{1}$. Additionally, many TMD sufferers may also complain of headache $^{2}$ and otologic symptoms such as ear-fullness, otalgia, hearing loss, tinnitus and vertigo ${ }^{3}$, although no cause-andeffect relationship between TMDs and aural symptoms has been yet definitively identified. Tinnitus, ear fullness, hearing loss and vertigo are also symptoms of Ménière's disease (MD), a disease of unknown aetiology which is frequently, but not exclusively, featured by the endolymphatic hydrops of the inner ear. TMDs have been more frequently documented in association with MD than in the general population, even if the co-occurrence rate is unknown. Moreover, Bjorne and Agerberg suggested an aetiological overlap of the two conditions, which is further strengthened by the improvement of otologic symptoms in MD sufferers after coordinated treatment of both temporomandibular and cervical spine disorders ${ }^{4}$. A more recent study showed that the use of a dental orthotic alone is effective in reducing tinnitus and dizziness in TMD-suffering patients ${ }^{5}$. It should be noticed that both the above-mentioned studies reported improvement of aural symptoms only by patients' subjective evaluation and no instrumental techniques. Therefore, the aim of this cohort, retrospective study was to evaluate the effectiveness of a splint therapy in relieving tinnitus and dizziness in patients suffering from MD and TMD, using audiological and vestibular tests as appropriate. Subjective evaluation of symptoms of MD, facial pain and headache were also investigated by the mean of disease-specific questionnaires.

\section{Materials and methods}

\section{Patients}

The medical reports of 2658 outpatients who attended the tertiary centre of audiology of the University Hospital of Modena (Italy) between 1 January 2017 and 31 December 2018 were retrieved. Among these, 108 cases diagnosed with definite MD, according to the international criteria of the Barany Society ${ }^{6}$, were selected. Finally, only the medi- cal reports of those patients who were also diagnosed with TMD-related pain, according to the rules of the Research Diagnostic Criteria for Temporomandibular Disorders consortium network and orofacial pain special interest group ${ }^{7}$ and who completed the prescribed occlusal splint therapy, were included. Medical reports of patients affected by intra-articular TMD, users of orthotic appliances and those undergoing orthodontic treatment at the time of the referral were not considered. Finally, 22 medical reports were selected. Among these, 10 subjects suffered from headache attributed to TMD (ICD-10, G44.89), 10 from myofascial pain (ICD-10 M79.1) and 2 from arthralgia (ICD-10 M26.62). The sample population was composed of Caucasian patients with a mean age of $38.6 \pm 6.9$ years (range: 28-51 years). Sixteen patients were female (72.7\%), 12 patients suffered for right MD and 10 for left MD. TMD was unilateral in 14 cases and bilateral in the others. All patients experienced persistent tinnitus, dizziness, otalgia, and subjective hearing loss in the interictal period. None underwent ablative surgery, while 6 patients had been previously submitted to intratympanic gentamicin injections procedure and 18 had received pharmacological prophylaxis (L-channel calcium channel antagonists, beta-blockers and betahistine dihydrochloride) lasting 6 months before starting the occlusal therapy. Only antiemetic medication, such as thiethylperazine maleate rectally and/or levosulpiride injections were used, if needed, during treatment.

\section{Stabilizing splint therapy}

Only when both the two senior dentists (C.Be, E.R) who examined MD patients agreed on the diagnosis of TMD, completed by temporomandibular joint computed tomography, a custom-fabricated hard acrylic splint fitting over the occlusal and incisal surfaces of the maxillary teeth was delivered. This full-coverage hard acrylic occlusal appliance (stabilisation splint-SS) is currently supposed to reduce neuromuscular hypertone of the temporalis and masseter muscles, thus obtaining stable occlusal relationships with uniform tooth contacts throughout the dental arch and stabilizing temporomandibular joints. Obviously an in-depth description regarding the step-by-step construction of SS is beyond the scope of the present article. All patients were asked to wear the SS at night, while sleeping, starting from the night after its delivery. Since SS might be adjusted as the masticatory muscles relax, all patients' splints were checked monthly and adjusted to maintain a stable contact relationship with each opposing mandibular tooth in the position of relaxed closure.

\section{Otoneurological examination}

Data were extracted from two consecutive clinical assessments, scheduled 6 months apart from each other, in the 
interval period of the MD. This time interval was based on a previous study that appreciated a significant reduction of otologic symptoms in TMD-affected patients undergoing occlusal therapy ${ }^{5}$. The mean pure-tone audiometry thresholds (PTA) for air and bone conduction at 0.5, 1, 2, and $4 \mathrm{kHz}$ were calculated $[\mathrm{PTA}=$ (threshold at $0.5 \mathrm{kHz}+1$ $\mathrm{kHz}+2 \mathrm{kHz}+4 \mathrm{kHz}) / 4$ ], according to the accepted standards (ISO 8253-1, 1989). Only air-conduction hearing threshold of the affected ear was reported and the stage of the disease classified as follows: stage I, PTA $<26 \mathrm{~dB}$; stage II, $26<$ PTA $<40 \mathrm{~dB}$; stage III, $41<$ PTA $<70 \mathrm{~dB}$; and stage IV, PTA $>70 \mathrm{~dB}$. Acoustic immittance was recorded by an impedenzometer. The maximum pressure (expressed in $\mathrm{daPa}$ ) and the peak compliance (expressed in $\mathrm{mm}$ ) were recorded before and after occlusal therapy. Electronystagmographic study of spontaneous nystagmus recorded binocularly in primary gaze and in the darkness was performed: if the average slow phase velocity, calculated over a $20 \mathrm{~s}$ period, was below $3 \%$, the nystagmus was considered not significant. Also, bithermal irrigation $\left(33^{\circ} \mathrm{C}\right.$ and $\left.44^{\circ} \mathrm{C}\right)$ of both ear canals was performed and the vestibular paresis formula of Jongkees was used. Caloric hypo-responsiveness was defined as more than a $25 \%$ asymmetry. DixHallpike and Semont manoeuvers were always performed to detect positional/paroxysmal nystagmus by the mean of videonystagmoscopy. Cervical vestibular-evoked myogenic potentials (cVEMPs) were performed to test ipsilateral saccular function. Each subject was tested while supine, the head raised $30^{\circ}$ from the horizontal plane to provoke the contraction of the sternocleidomastoid muscle. The active electrode was placed on the middle third of the sternocleidomastoid muscle and a reference electrode was placed on the upper border of the sternum. The ground electrode was placed on the forehead. Acoustic stimuli were short-tone bursts with a frequency of $500 \mathrm{~Hz}$, presented five times per second through a TDH-49 earphone, in the affected ear. The rise-plateau-fall time was 1-2-1. cVEMPs responses were initially obtained by an acoustic stimulus of $95 \mathrm{~dB}$ HL and only if responses were absent it was increased to 100 $\mathrm{dB}$ HL. The duration of the stimulus was $10 \mathrm{msec}$. Results from 200 repetitions in each ear were averaged. The mean peak latencies (expressed in msec) of the P13 and N23 waves of cVEMPs were measured. The rectified amplitude was calculated by dividing the raw peak-to-peak amplitude $(\mathrm{dB})$ by the background electromyography activity recorded during the $20 \mathrm{msec}$ interval prior to the stimulus onset. The test was performed twice to test reproducibility. The number of vertigo attacks in the six months before and throughout occlusal therapy was extracted by a selfrate vertigo diary. Static stabilometry results were recorded before and at the end of the occlusal therapy using a force platform sensitive to vertical force. The force-plate was mounted on 3 strain-gauge force transducers, positioned at the vertices of an equilateral triangle, providing description of body sway in terms of displacement of the center of pressure (statokinesiogram-SKG). Patients stood barefoot on the platform with arms by their side and the displacements of their center of pressure (COP) were continuously detected over a period of $52.2 \mathrm{sec}$ with a sampling frequency of $50 \mathrm{~Hz}$, both with eyes opened (EO) and closed (EC). In particular, the area $\left(\mathrm{S}\right.$-expressed in $\left.\mathrm{mm}^{2}\right)$ and the length (L-expressed in $\mathrm{mm}$ ) of the SKG as well as the velocity of displacements of the COP (V- expressed in $\mathrm{mm} / \mathrm{s}$ ) were detected. The $\mathrm{S}$ was computed by continuously detecting the COP displacement over time and calculating a confidence ellipse that corresponds to the $90 \%$ of the sample positions, expressed in $\mathrm{mm}^{2}$.

After that, each patient was asked to face the wall in front of him/her, where a digital projector offered a full-field horizontal optokinetic $(\mathrm{OKN})$ stimulation represented by vertical alternating dark and light stripes of $30 \mathrm{~cm}$ in diameter, delivered at a speed of $30 \% \mathrm{sec}$. S, L and V were also measured during this stimulation, delivered towards the affected ear as well as the un-affected ear. This test was performed because OKN stimulations are known to impair visually-evoked postural responses in $\mathrm{MD}^{8}$. S, L and $\mathrm{V}$ values measured under OKN stimulation are indicated with S-OKN, L-OKN and V-OKN, respectively.

\section{Questionnaires}

Before and after each clinical assessment, patients were asked to fill in a standardised battery of self-administered questionnaires: the Numeric Pain Rating Scale (NPRS) ${ }^{9}$, the Tinnitus Handicap Inventory (THI) ${ }^{10}$ and the Situational Vertigo Questionnaire (SVQ) ${ }^{11}$. The NPRS is a numeric tool in which a respondent selects a whole number $(0-10)$ that best reflects the intensity of pain in the last 24 hours. Numbers are located on a horizontal bar where 0 corresponds to "no pain" and 10 to the worst pain 9 . The THI is composed of 25 items, which score ranges from 0 to $4(0=$ never, $2=$ sometimes, $4=$ always $)$ and analyzes the functional limitation (12 questions), the emotional reactions (8 questions) and the catastrophic perception (5 questions) caused by tinnitus. The score ranges from 0 to 100; the higher the score, the higher the severity of tinnitus annoyance is ${ }^{10}$. The SVQ is a 19 -items questionnaire investigating the presence of visual vertigo, a disorder characterized by symptoms of dizziness, disorientation, and general discomfort induced by the presence of large moving objects in the visual field that often trigger dizziness in MD patients. In particular, SVQ investigate what visual environments, such as watching moving traffic or trains, can 
cause vertigo and how much: for every item a maximum of 4 points are given according to the stimuli ability to induce or worse vertigo, while 0 points are assigned if the stimuli are unable to cause it. If a patient did not experience one or more described situations, the answer should be "not experienced". The overall score is given by the following formula: Total score/(19- number of questions in which patient signed "not experienced") ${ }^{11}$.

\section{Statistical analysis}

Continuous data were expressed as mean \pm standard deviation, while categorical ones were indicated as subjectcounts and percentages. Continuous variables were compared using the one-way analysis of variance followed by the Tuckey-Kramer post-hoc comparison test. Categorical variables were compared using Fisher's exact test. Statistical calculations were made using STATA Ic13 software. Pvalues lower than 0.005 were considered significant.

\section{Results}

MD lasted for a mean time of $15 \pm 4$ years, while the mean length of TMD history was $(3 \pm 0.7)$ years. At baseline, 8 patients $(36.5 \%)$ were classified in stage II, 13 patients (59 \%) in stage III and only 1 patient $(4.5 \%)$ in stage IV of the MD. The same percentages were recorded at the end of the treatment. No correlation was found between the side of unilateral MD and unilateral TMD $(\mathrm{p}=0.7952)$. The configuration of the audiogram was pike's peak in 6 patients $(27.3 \%)$, flat in 14 patients $(63.6 \%)$ and rising in two $(9.1 \%)$. PTA at the baseline was $(47.23 \pm 13.7) \mathrm{dB}$ and $(46.9 \pm 13.9) \mathrm{dB}$ at the final assessment $(\mathrm{p}=0.9354)$. All patients exhibited a type A tympanogram according to the Jerger's classification system and, in the affected ear, none showed a gap between bone and air conduction hearing threshold exceeding $10 \mathrm{~dB}$. Middle ear pressure was $(0.91 \pm 0.32) \mathrm{daPa}$ at the baseline and $(0.88 \pm 0.24) \mathrm{daPa}$ after the treatment, while compliance varied from $(1.9 \pm 29.1)$ to $(-11.8 \pm 29.8)$; no significant differences were found for either parameter ( $\mathrm{p}=0.847$ and $\mathrm{p}=0.204$, respectively).
Electronystagmography showed no significant spontaneous nystagmus in any patient before and after treatment. Jonkees's formula applied to caloric tests responses documented a caloric hypo-responsiveness in 18 patients before occlusal therapy and in 19 at the end. The mean canal caloric asymmetry was $(29.1 \pm 7.7)$ at the beginning of the occlusal therapy and $(30.2 \pm 6.7)$ at the end $(p=0.102)$. No paroxysmal positional nystagmus was detected at the time of the two consecutive examinations. The mean peak latency of the P13 and N23 wave of the cVEMPs at the baseline were $(16.8 \pm 1.6) \mathrm{msec}$ and $(25.9 \pm 1.7) \mathrm{msec}$; after occlusal splint therapy, P13 latency was $(15.8 \pm 2) \mathrm{msec}$ and N23 latency was $(24.9 \pm 2.1) \mathrm{msec}$, showing no significant differences ( $\mathrm{p}=0.069$ and $\mathrm{p}=0.089$, respectively). Rectified peak-to-peak amplitude was (1.72 \pm 0.3$) \mathrm{dB}$ before occlusal therapy and $(1.67 \pm 0.28) \mathrm{dB}$ after it, showing no significant difference $(\mathrm{p}=0.605)$. cVEMPs could not be elicited in 6 patients $(27.3 \%)$ at the two consecutive assessments. These results are summarised in Figure 1. The number of crises significantly decreased from $(2.2 \pm 1.7)$ to $(0.9 \pm 1.3)(p=0.003)$. No differences were found between the $\mathrm{S}, \mathrm{L}$ and $\mathrm{V}$ parameters under $\mathrm{EO}$ conditions at baseline and after 6 months (all p >0.005), while all of them were significantly reduced in the EC condition (all p < 0.0001) (Tab. I). The horizontal OKN stimulation displayed a significant reduction of S-OKN ( $\mathrm{p}<0.0001)$, L-OKN and $\mathrm{V}$ OKN ( $\mathrm{p}<0.0001)$ during its delivery toward the afflicted side after SS treatment. No differences of S-OKN, L-OKN and $\mathrm{V}-\mathrm{OKN}$ were observed if the same optic stimulation was delivered towards the unaffected side $(\mathrm{p}>0.005$ in all parameters). The mean slow phase velocity and the total number of saccades of the optokinetic reflex (OKN-SPV) did not vary from baseline to final assessment if the optic flow was delivered in both directions (all $\mathrm{p}>0.005$ ) (Tab. II). The mean value of the NPRS at baseline was $(4.7 \pm 1.7)$ and after 6 months of occlusal splint therapy was significantly reduced to $1.4 \pm 1.1(\mathrm{p}<0.0001)$ thus suggesting a relevant pain relief. The total score of the THI significantly decreased from the first administration (33.6 \pm 9.1$)$ to the final one $(21.4 \pm 5.1)(\mathrm{p}<0.0001)$, showing a general

Table I. Stabilometric parameters under EO and EC conditions.

\begin{tabular}{lccc} 
Variable & Baseline & $\mathbf{6}$ months & P-value \\
L-EO & $464.07 \pm 103.61$ & $437.06 \pm 85.43$ & 0.4436 \\
L-EC & $613.68 \pm 102.81$ & $427.76 \pm 110.96$ & $<0.0001$ \\
S-EO & $227.23 \pm 100.63$ & $194.36 \pm 82.57$ & 0.243 \\
S-EC & $491.23 \pm 241.78$ & $313.91 \pm 122.89$ & $<0.0001$ \\
V-EO & $13.51 \pm 1.92$ & $12.12 \pm 2.35$ & 0.057 \\
V-EC & $15.11 \pm 1.24$ & $11.71 \pm 3.06$ & $<0.0001$ \\
\hline
\end{tabular}

L: statokinesiogram length; S: statokinesiogram surface; V: velocity of the displacements of the centre of pressure; EO: eyes opened; EC: eyes closed. 
Table II. Stabilometric parameters and electronystagmography recordings of the optokinetic nystagmus recorded with optokinetic stimulations delivered toward the affected ear and the intact one.

\begin{tabular}{lccc} 
Variable & Baseline & $\mathbf{6}$ months & P-value \\
OKN-L, affected side & $733.94 \pm 104.66$ & $460.28 \pm 120.27$ & $<0.0001$ \\
OKN-L, unaffected side & $512.48 \pm 68.48$ & $478.92 \pm 75.93$ & 0.0991 \\
OKN-S, affected side & $588.73 \pm 323.68$ & $363.68 \pm 190.74$ & 0.002 \\
OKN-S, unaffected side & $356.95 \pm 145.71$ & $344.27 \pm 140.29$ & 0.7702 \\
OKN-V, affected side & $15.73 \pm 1.69$ & $11.03 \pm 1.95$ & $<0.0001$ \\
OKN-V, unaffected side & $13.32 \pm 1.6$ & $12.27 \pm 2.1$ & 0.0836 \\
OKNSPV-affected side & $9.69 \pm 2.15$ & $9.12 \pm 1.39$ & 0.2 \\
OKNSPV-unaffected side & $13.08 \pm 1.25$ & $12.62 \pm 1.72$ & 0.3127 \\
Sacc-affected side & $21.55 \pm 3.65$ & $22.73 \pm 1.45$ & 0.0987 \\
Sacc-unaffected side & $26.55 \pm 1.22$ & $26.27 \pm 1.08$ & 0.4088 \\
\hline
\end{tabular}

OKN-L: statokinesigram length under optokinetic stimulation; OKN-S: statokinesogram surface under optokinetic stimulation; OKN-V: velocity of the displacements of the center of pressure under optokinetic stimulation; OKNSPV: slow phase velocity of the optokinetic nystagmus; Sacc: number of saccadic movements of the optokinetic nystagmus.

improvement of tinnitus annoyance. The 'functional' subscale score showed indeed the most significant difference $(\mathrm{p}<0.0001)$ between baseline $(19.3 \pm 6.6)$ and final assessment $(11.1 \pm 5.1)$, the 'emotional' subscale score decreased from $(11.2 \pm 5)$ to $(8.3 \pm 2.5)$ disclosing a less remarkable reduction $(\mathrm{p}=0.025)$ and the 'catastrophic' subscale score resulted $(3.1 \pm 2.9)$ at first assessment and $(2.1 \pm 2.2)$ after occlusal therapy and unchanged $(\mathrm{p}=0.131)$. The SVQ score was $(3.3 \pm 0.5)$ before treatment and $(2.6 \pm 0.7)$ at the end of it and showed a significant reduction $(\mathrm{p}=0.002)$. This data is summarised in Figure 2.

\section{Discussion}

TMDs have been associated with audiometrically documented hearing loss ${ }^{12}$ but no study, to our knowledge, has reported significant, objective amelioration of hearing threshold after occlusal splint therapy or any other therapy for TMDs. Additionally, our study showed no improvement of the PTA. It should be also observed that all patients suffered from definite MD and its mean duration was about fifteen years. So far, it is conceivable that hearing loss at the time of the occlusal treatment was no longer fluctuating and reversible as in the first stages of the disease and histopathological changes in the cochlea are presumably permanent. It is also conceivable that SS therapy per se is not capable of modifying cochlear damage in humans. Furthermore, middle ear pressure and compliance did not differ before and after occlusal therapy and resulted within normal ranges in all cases $(-100<\mathrm{daPa}<100$ and $0.3<\mathrm{ml}<1.5$ respectively). This result seems to exclude that the pathophysiology of some aural symptom associated to TMDs such as ear-fullness, tinnitus and subjective hearing loss could be identified in a perturbed ventilation of the Eustachian tube due to an abnormal contraction or spasm of the tensor veli palatini muscles. Caloric responses were stable between the two assessments (Fig. 1) and the paroxysmal positional nystagmus due to otolith dysfunction was absent, thus excluding the coexistence of other vestibular end-organ disorders at the time of the two examinations. The rate of occurrence of vertigo attacks was interestingly reduced during the occlusal treatment compared to the previous period. Past experiments stated that ipsilateral dark cell region of the vestibular ampullas receives afferent fibers from the trigeminal ganglion and the trigeminal innervation to the cochlear blood vessels could be involved in the homeostatic disturbances of the inner ear, such as hydrops, in guinea pigs ${ }^{13}$. Unfortunately, analogous pathophysiological data are not available in humans and a cause-effect mechanism between an abnormal trigeminal nociceptive pattern caused by TMDs in MD patients and a possible decrease of vertigo attacks as a consequence of occlusal therapy remains elusive. Moreover, the reduction of acute attacks of vertigo could be also due to the natural history of the disease or to amelioration of the TMD only. Obviously, occlusal splint may ameliorate patients' stability, thus improving vertigo as well.

In this study, an amelioration of the stabilometric parameters such as L, S and V in EC conditions only when the OKN was delivered towards the affected labyrinth denotes a central function of the occlusal splint itself. The study also showed the stationary nature of P13-N23 latency and rectified inter-peak amplitude of cVEMPs over the selected time interval (Fig. 1). This result must be interpreted with caution because, to our knowledge, no prospective studies have explored the behaviour of sacculo-collic reflexes in MD over time. On the contrary, a conservative occlusal therapy carried on by SS may be an effective option to im- 


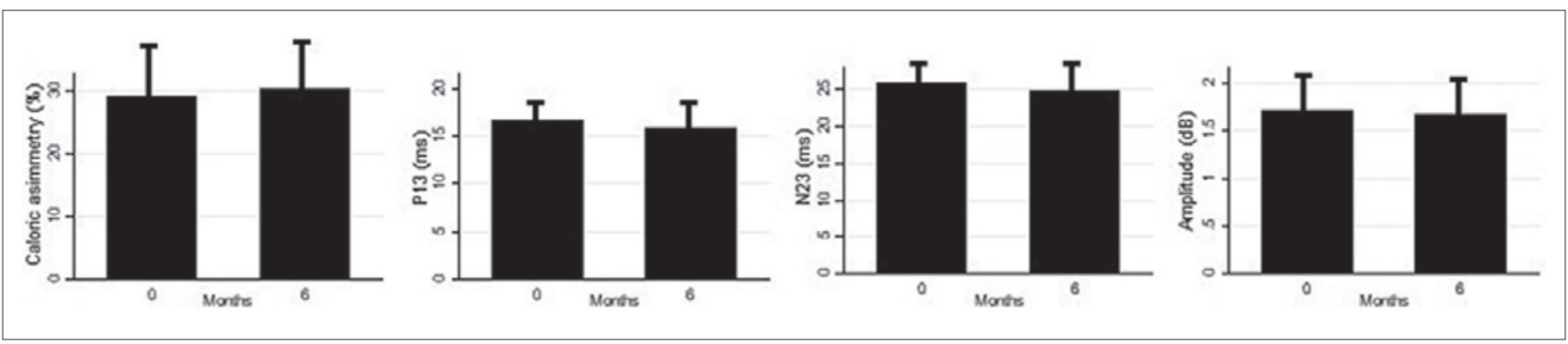

Figure 1. Caloric asymmetry, P13 and N23 peak latencies and amplitude before and after occlusal splint therapy ( $p>0.005$ in all cases).

prove body balance in patients suffering for TMDs and coexisting MD. It should be underlined that the improvement of body sway parameters has been observed only in the EC condition and when OKN stimulation was delivered to the afflicted ear. The lack of significant postural improvement under EO conditions between baseline and the end of treatment confirms the results of a previous experience that documented the efficacy of static visual cues on counteracting vestibular and somatosensory abnormal information in patients with peripheral vestibular dysfunctions and comorbid TMD ${ }^{14}$. In contrast, the lack of visual information causes vestibular impairment and the abnormal proprioceptive pattern of the stomatognathic apparatus of these patients to emerge, giving reason for the higher values of $\mathrm{S}$, $\mathrm{L}$ and $\mathrm{V}$ both at the baseline and after 6 months of SS, if compared to the EO conditions. In fact, stabilometric parameters were markedly improved after occlusal therapy in the EC condition. A possible pathophysiological explanation of this therapeutic effect is based on an experience that observed trigeminal terminals in contact with vestibulospinal neurons in the inferior and lateral vestibular nuclei, giving evidence of a trigemino-vestibulospinal pathway in rats ${ }^{15}$. In humans, such connections are not known and their existence could only be suspected. On the contrary, recent fMRI studies in humans clearly demonstrated that splint therapy triggers activation in parietal sensorimotor integration areas that are also involved in the processing

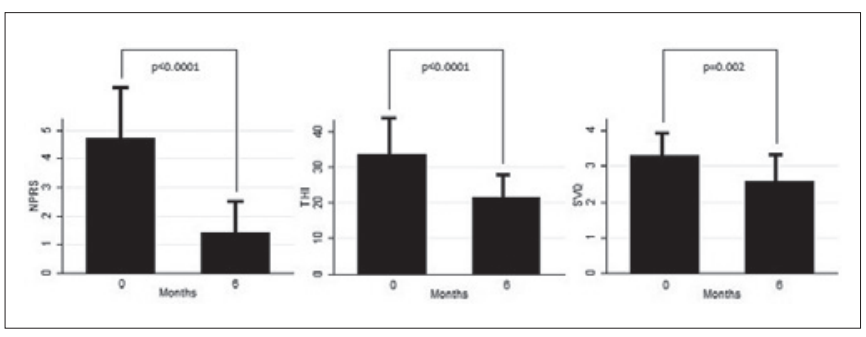

Figure 2. Numeric Pain Rating Scale (NPRS) score, Tinnitus Handicap Inventory $(\mathrm{THI})$ and Situational Vertigo Questionnaire (SVQ) before and after occlusal splint therapy. of sensory information and modulation of postural reflexes and gait ${ }^{16}$. Moreover, vestibular ascending pathways are known to reach the insula in humans ${ }^{17}$ and both a posterior and an anterior pain-related cortical area have been described within the insular cortex ${ }^{18,19}$. Finally, robust vestibular stimulation is known to activate the anterior cingulate cortex ${ }^{20}$ that is also activated by noxious stimuli and is involved in pain processing ${ }^{21}$.

Taken together, these data suggest that the stabilising effect of splint therapy on postural control may be more probably attributed to a reduced interference of pain on the cortical vestibular network rather than to a peripheral vestibular mechanism. In fact, no documented and significant changes occurred in the inner ear while pain was rated as greatly reduced after occlusal therapy. Given this, an analogous central mechanism could also explain the improvement of postural responses to optokinetic stimulation of MD patients who are known to be particularly sensitive to moving visual scenes ${ }^{8}$. Both the anterior and the posterior insula and the anterior cingulate cortex are activated during optokinetic nystagmus ${ }^{22}$. Balance amelioration in response to moving visual cues is also supported by the significant reduction in the SVQ score after occlusal therapy in this study. The significant decrease in the SVQ score indicates that a lower number of visual triggers and/or their frequency are able to induce vertigo/dizziness. This result suggests reduced sensitivity to moving visual environments of patients with vestibular disorders as a consequence of more effective central integration of conflicting sensory information from visual and vestibular receptors. The improvement of tinnitus showed by this study has been already documented in patients treated by a multimodal therapeutic approach for TMD and comorbid MD ${ }^{5}$, thus supporting the hypothesis of an abnormal somatosensory component in the origin and/or persistence of tinnitus in TMD sufferers ${ }^{23}$. In fact, in humans trigeminal-auditory anatomical connections are far from being documented even if the modulation of tinnitus by jaw manoeuvers is widely diffuse among acute and chronic tinnitus sufferers ${ }^{24}$. At present, it is reason- 
able to suggest that improvement of tinnitus annoyance in this cohort is more probably due to the reduction of the hypertone of masticatory muscles ${ }^{25}$ obtained by SS rather than to a substantial change in both the middle and the inner ear. Some potential limitations of the current study are noteworthy. For example, we did not perform any kind of acuphenometry to assess pitch and loudness of tinnitus in order to objectify basic features. Nonetheless, the use of a symptom-specific questionnaire like the THI is probably more appropriate to assess the beneficial effects of any therapy in tinnitus-sufferers since tinnitus perceived handicap is largely independent from its audiometrically-derived measures ${ }^{16}$. The study design did not include untreated participants as controls or a comparison group treated with non-occluding oral appliances (active placebo). On the other hand, effective therapy for TMDs must not be deliberately avoided in patients suffering from such symptoms only to appreciate a placebo effect or the result of no treatment. Finally, the sample size was small and even if it was from a hypothesis-generating study, a larger, multicentre confirmatory study is needed.

\section{Conclusions}

An SS appliance can be a conservative and safe treatment option for patients suffering from TMD and comorbid MD because of an increased control of visually-evoked postural responses and better vestibulo-spinal control of posture when visual cues are not available. Head and oro-facial pain amelioration is also obtained by occlusal therapy and might increase patients' quality of life. The reduction of vertigo attacks and tinnitus annoyance should also contribute to it, even if further studies with adequate questionnaires that specifically investigate quality of life are needed. In contrast, sensorineural hearing loss due to definite MD should be considered as an irreversible sensory deprivation with no existing effective treatment except for aural rehabilitation with hearing devices. The therapeutic mechanisms of stabilisation splints in patients with TMDs and comorbid Ménière's disease should be further investigated within the framework of prior experimental data on cortical areas that process both vestibular and trigeminal afferent signals in humans.

\section{Conflict of interest statement}

CB received travel grants from Allergan, Teva, Novartis and Ely Lilly. SG received travel grants and honoraria from Allergan, Teva, Novartis and Eli Lilly. In the last year LP is the Chief Scientific Officer of EDRA-LSWR Publishing Company and of Inpeco SA Total Lab Automation Company. In the last year he has been a scientific consultant to
AbbVie, USA; BCG, Switzerland; Boehringer-Ingelheim, Germany; Compass Pathways, UK; EDRA-LSWR, Italy; Inpeco SA, Switzerland; Relmada, USA; Johnson \&amp; Johnson, USA; Takeda, USA; VeraSci, USA; Vifor, Switzerland. DM, EA, MAC, CBe, ER and DMa have no conflict of interests to declare.

\section{Funding}

This research did not receive any specific grant from funding agencies in the public, commercial, or not-for-profit sectors.

\section{Authors' contributions}

DMo, DMa, MAC and LP conceived the study. CBa, EA, $\mathrm{ER}, \mathrm{CBe}, \mathrm{MAC}$ and $\mathrm{SG}$ recruited patients. CBa, SG, LP and DM made statistical calculations. All authors read and approved the last version of the manuscript.

\section{Ethical consideration}

This retrospective study was approved by the Modena Ethics Committee (protocol number: 2121, study code NOC11) and each participant signed an informed consent for study participation and data publication. All procedures were conducted in accordance with the latest version of the declaration of Helsinki.

\section{References}

1 Liu F, Steinkeler A. Epidemiology, diagnosis, and treatment of temporomandibular disorders. Dent Clin North Am 2013;57:465-479. https://doi.org/10.1016/j.cden.2013.04.006

2 Di Paolo C, D'Urso A, Papi P, et al. Temporomandibular disorders and headache: a retrospective analysis of 1198 patients. Pain Res Manag 2017;2017:3203027. https://doi.org/10.1155/2017/3203027

3 Porto De Toledo I, Stefani FM, Porporatti AL, et al. Prevalence of otologic signs and symptoms in adult patients with temporomandibular disorders: a systematic review and meta-analysis. Clin Oral Investig 2017;21:597-605. https://doi.org/10.1007/s00784-016-1926-9

4 Bjorne A, Agerberg G. Symptom relief after treatment of temporomandibular and cervical spine disorders in patients with Meniere's disease: a three-year follow-up. Cranio 2003;21:50-60. https://doi. org/10.1080/08869634.2003.11746232

5 Wright EF, Syms CA 3rd, Bifano SL. Tinnitus, dizziness, and nonotologic otalgia improvement through temporomandibular disorder therapy. Mil Med 2000;165:733-736.

6 Lopez-Escamez JA, Carey J, Chung WH, et al. Diagnostic criteria for Ménière's disease. J Vestib Res 2015;25:1-7. https://doi:10.3233/ VES-150549

7 Schiffman E, Ohrbach R, Truelove E, et al. Diagnostic criteria for temporomandibular disorders (DC/TMD) for clinical and research applications: recommendations of the International RDC/TMD consortium network and orofacial pain special interest group. J Oral Facial Pain Headache 2014;28:6-27. https://doi.org/10.11607/jop.1151

8 Cusin FS, Ganança MM, Ganança FF, et al. Balance Rehabilitation Unit (BRU) posturography in Menière's disease. Braz J Otorhinolaryngol 2010;76:611-617. 
9 Kahl C, Cleland JA. Visual analogue scale, numeric pain rating scale and the McGill pain Questionnaire: an overview of psychometric properties. Phys Ther Rev 2005;10:123-128. https://doi. org/10.1179/108331905X55776

10 Monzani D, Genovese E, Marrara A, et al. Validity of the Italian adaptation of The Tinnitus Handicap Inventory; focus on quality of life and psychological distress in tinnitus-sufferers. Acta Otorhinolaryngol Ital 2008;28:126-134.

11 Colnaghi S, Rezzani C, Gnesi M, et al. Validation of the Italian version of the Dizziness Handicap Inventory, the Situational Vertigo Questionnaire, and the Activity-Specific Balance Confidence Scale for peripheral and central vestibular symptoms. Front Neurol 2017;8:528. https://doi.org/10.3389/fneur.2017.00528

12 Kirby SE, Yardley L. Physical and psychological triggers for attacks in Ménière's disease: the patient perspective. Psychother Psychosom 2012;81:396-368. https://doi.org/10.1159/000337114

13 Effat KG. Otological symptoms and audiometric findings in patients with temporomandibular disorders: Costen's syndrome revisited. J Laryngl Otol 2016;130:1137-1141. https://doi.org/10.1017/ S0022215116009300

14 Vass Z, Shore SE, Nuttall AL, et al. Endolymphatic hydrops reduces retrograde labeling of trigeminal innervation to the cochlea. Exp Neurol 1998;151:241-248. https://doi.org/10.1006/exnr.1998.6813

15 Monzani D, Guidetti G, Chiarini L, et al. The combined effect of vestibular and craniomandibular disorders on postural behavior. Acta Otorhinolaryngol Ital 2003;23:4-9.

16 Diagne M, Valla J, Delfini C, et al. Trigeminovestibular and trigeminospinal pathways in rats: retrograde tracing compared with glutamic acid decarboxylase and glutamate immunohistochemistry. J Comp Neurol 2006;496:759-772. https://doi.org/10.1002/cne.20964

17 Lickteig R, Lotze M, Kordass B. Successful therapy for temporomandibular pain alters anterior insula and cerebellar representa- tions of occlusion. Cephalalgia 2013;33:1248-1257. https://doi. org/10.1177/0333102413491028

18 Lickteig R, Lotze M, Lucas C, et al. Changes in cortical activation in craniomandibular disorders during splint therapy - a single subject fMRI study. Ann Anat 2012;194:212-215. https://doi,org/10.1016/j. aanat.2011.10.006

19 Shinder ME, Taube JS. Differentiating ascending vestibular pathways to the cortex involved in spatial cognition. J Vestib Res 2010;20:3-23. https://doi.org/10.3233/VES-2010-0344

20 Ostrowsky K, Magnin M, Ryvlin P, et al. Representation of pain and somatic sensation in the human insula: a study of responses to direct electrical cortical stimulation. Cereb Cortex 2002;12:376-385. https:// doi.org/10.1093/cercor/12.4.376

21 Xiao X, Zhang YQ. A new perspective on the anterior cingulate cortex and affective pain. Neurosci Biobehav Rev 2018;90:200-211. https:// doi.org/10.1016/j.neubiorev.2018.03.022

22 Dieterich M, Bucher SF, Seelos KC, et al. Horizontal or vertical optokinetic stimulation activates visual motion-sensitive, ocular motor and vestibular cortex areas with right hemispheric dominance. An fMRI study. Brain 1998;121:1479-1495. https://doi.org/10.1093/ brain/121.8.1479

23 Unell L, Ström D, Ekman K, et al. A 3-year study of patients with tinnitus and jaw muscle tenderness. Cranio 2019;37:304-309. https:// doi.org/10.1080/08869634.2018.1430097

24 Ralli M, Greco A, Turchetta R, et al. Somatosensory tinnitus: current evidence and future perspectives. J Int Med Res 2017;45:933-947. https://doi.org/10.1177/0300060517707673

25 Daif ET. Correlation of splint therapy outcome with the electromyography of masticatory muscles in temporomandibular disorder with myofascial pain. Acta Odontol Scand 2012;70:72-77. https://doi.org/ 10.3109/00016357.2011.597776 